\title{
Research on effectiveness evaluation method and application of quality management system of manufacturing enterprise based on interval-valued hesitation fuzzy set
}

\author{
Yu Chen Yao \\ Business School of Hohai University, Nanjing, P. R. China \\ E-mail: 326603581@qq.com
}

Received 3 August 2017; accepted 14 August 2017

DOI https://doi.org/10.21595/vp.2017.18937

Check for updates

\begin{abstract}
Based on acquaintance of effectiveness of quality management system of manufacturing enterprise, the evaluation index system is structured by confirmation of production conditions and other seven respects which include effectiveness of validation, effectiveness of document management, effectiveness of production management, effectiveness of quality assurance and quality control, effectiveness of commissioned production and inspection, effectiveness of Issue and recall of products and effectiveness of self-checking; the assessment model of effectiveness of quality management system of manufacturing enterprise based on interval-valued hesitation fuzzy set is structured and the feasibility of theoretical research was validated by concrete cases.
\end{abstract}

Keywords: effectiveness of quality management system, evaluation methods, interval-valued hesitation fuzzy set.

\section{Introduction}

Under the background of economic integration trend to strengthen, Chinese companies are facing greater pressure of market competition, which is about not only domestic enterprises but also foreign enterprise. Companies can get a better development by widening the market, which include the advance of market share of enterprises and the widen of international market. There is a different and necessary way to enhance companies by improving their own management, which include the construction and dynamic management of quality management system, the improvement of enterprise own development ability and the construction of unique enterprise core competitiveness.

Enterprise management system is aimed at induction and summary of a series of managements, is systematic content, is the organic unity of the enterprise management activities, the rules and regulations and the management way. One of the most necessary content of the survival and development of the enterprise is quality management system for manufacturing enterprise. Thus, the manufacturing enterprise must strengthen quality management system to ensure the efficiency of management of manufacturing enterprise [1].

It is not enough that manufacturing enterprises only have quality management system. Because of the development of the manufacturing enterprises itself and the development of macro environment, industry environment and regional environment, manufacturing enterprises should adjust the quality management system of enterprises to ensure the effectiveness of the quality management system and meet the need of enterprises development. Manufacturing enterprises deciding whether they need to conduct its own quality management system by adjusting the effectiveness of quality management system [2]. Due to effectiveness of manufacturing enterprise quality management system is embodied in many aspects, effectiveness evaluation model that can handle the multi-index problem and comprehensive evaluation index system of manufacturing enterprise quality management system effectiveness is built by analyzing the characteristics of management of manufacturing enterprises and affecting factors of effectiveness of manufacturing enterprise quality management system. 
Based on the above analysis, this research is aimed at effectiveness evaluation of manufacturing enterprise quality management system, and it plays an important role in promoting business management theories and solving manufacturing enterprise managed problems.

\section{Definition on effectiveness of quality management system of manufacturing enterprise}

\subsection{Definition on effectiveness of quality management system of manufacturing enterprise}

Quality management system and effectiveness evaluation should be defined before effectiveness of quality management system of manufacturing enterprises is defined.

Quality management system can be defined by following words: the organization adopt series of management methods, such as organization, technology, economy, contract and so on, to achieve the goal of quality management, which include relevant government regulations, industry standards, and specific requirements.

Effectiveness evaluation can be defined by following words: the estimator can assess the value of activities and judge the outcome of activities by setting the target and measures.

Based on the definition of quality management system and effectiveness evaluation, evaluation on the effectiveness of the quality management system of manufacturing enterprises can be defined by following:

Evaluation on the effectiveness of the quality management system of manufacturing enterprises is an activity, which is used to analysis the positive influence in the process of normal operations by making evaluation standard, determining the size of the influence and getting the special judgment.

\subsection{Overall thinking on construction of quality management effect evaluation index system of manufacturing enterprises}

According to the above analysis, the evaluation on the effectiveness of the quality management system of manufacturing enterprises is an activity, which is used to analysis the positive influence in the process of normal operations by making evaluation standard, determining the size of the influence and getting the special judgment. And evaluation on the effectiveness of the quality management system of manufacturing enterprises mainly involves two aspects: one is the construction of evaluation index system on the effectiveness of the quality management system of manufacturing enterprises, the other is the construction of evaluation model on the effectiveness of the quality management system of manufacturing enterprises. Meanwhile the specific operation of effectiveness of the quality management system and feedback and summary of effectiveness evaluation results are involved in the evaluation on the effectiveness of the quality management system of manufacturing enterprises [3].

Thus the evaluation on the effectiveness of the quality management system of manufacturing enterprises should follow the following procedure: firstly, evaluation index system on the effectiveness of the quality management system of manufacturing enterprises should be built by analyzing the characters and affecting factors of quality management of manufacturing enterprise, combining with the relevant provisions of the existing, following the principles of establishing the index system and according to the first-class-second-class sequence; secondly, evaluation model of effectiveness on quality management system of manufacturing enterprise should be built. because many aspects are involve in the effectiveness of the quality management system of manufacturing enterprises, mathematical model of multiple index values should be built in the process of evaluation on the effectiveness of the quality management system of manufacturing enterprises; thirdly, evaluation on the effectiveness of the quality management system of manufacturing enterprises can be operating by building the mathematical model and evaluation index system of effectiveness of the quality management system of manufacturing enterprises; finally, analyzing the evaluation results of effectiveness on quality management system of 
manufacturing enterprise and reflecting the situation on the quality management system of manufacturing enterprises to improve the quality management system of manufacturing enterprise.

\section{Establishment of index system and method of weight determination on effectiveness evaluation of manufacturing enterprise quality management system}

\subsection{Establishment of index system}

To ensure the reliability and practicability of the index system construction, the systematic principle, the typical principle, the principle of operation and quantification, and comprehensive principle should be followed and thinking of first-class index system - second-class index system should be followed in the process of developing the effectiveness evaluation index system of manufacturing enterprise quality management system.

\subsubsection{Establishment of first-class index system}

Carrying out the manufacturing enterprise quality management system effectiveness evaluation is used to timely asses the effectiveness of the size of the quality management system and provide support for manufacturing enterprises timely detection of problems and deficiencies existing in its own quality management system. So, effectiveness evaluation index system on manufacturing enterprise quality management system should be built by following the relevant principle and consulting he content of the quality management system of the manufacturing enterprise and the requirement of the enterprise quality management system in the country.

First-class index system for evaluating the effectiveness of manufacturing enterprise quality management system should be composed of 7 first level indicators, which include effectiveness of validation, effectiveness of document management, effectiveness of production management, effectiveness of quality assurance and quality control, effectiveness of commissioned production and inspection, effectiveness of Issue and recall of products and effectiveness of self-checking.

\subsubsection{Establishment of second-class index system and formation of index system}

After the first-class index system on effectiveness evaluation of quality management system of manufacturing enterprise is established, the problem is establishment of second-class index system which can reflect the characteristics of the first-class index system to form a evaluation index system on effectiveness of manufacturing enterprise quality management system.

Evaluation index system of effectiveness of manufacturing enterprise quality management system is summarized in Table 1.

Something can be seen from the Table 1 that the evaluation index system is structured by seven first-class indexes which include effectiveness of validation, effectiveness of document management, effectiveness of production management, effectiveness of quality assurance and quality control, effectiveness of commissioned production and inspection, effectiveness of Issue and recall of products and effectiveness of self-checking, and each first-class index can be reflected through a number of second-class indexes. Finally, the index system, which has seven first-class indexes and twenty-seven second-class indexes, is built, and it can reflect the effectiveness of the quality management system of the manufacturing enterprise overall.

\subsection{Determination of weight of index system}

This paper makes an attempt to determine the weight of indexes through GAHP. The basic idea of this method is to determine the weight of indexes using AHP by experts respectively based on which the arithmetic mean value of evaluation results from experts are taken as the final result. This method makes up for the traditional AHP can only be determined by a single index weight problem [4]. 
Table 1. Evaluation index system of effectiveness of manufacturing enterprise quality management system

\begin{tabular}{|c|c|c|}
\hline The target layer & First-class index & Second-class index \\
\hline \multirow{27}{*}{$\begin{array}{l}\text { The } \\
\text { effectiveness of } \\
\text { the quality } \\
\text { management } \\
\text { system of } \\
\text { manufacturing } \\
\text { enterprises }\end{array}$} & \multirow{4}{*}{$\begin{array}{l}\text { Effectiveness of } \\
\text { validation } X_{1}\end{array}$} & Verification and validation of institutions and personnel $X_{11}$ \\
\hline & & Validation and verification of plant and facility $X_{12}$ \\
\hline & & Verification and validation of equipment $X_{13}$ \\
\hline & & Verification and validation of materials and products $X_{15}$ \\
\hline & \multirow{5}{*}{$\begin{array}{l}\text { Effectiveness of } \\
\text { document } \\
\text { management } X_{2}\end{array}$} & Quality standard $X_{21}$ \\
\hline & & Processing procedure $X_{22}$ \\
\hline & & Production records $X_{23}$ \\
\hline & & Packaging record $X_{24}$ \\
\hline & & Procedures, processes, and records of operation $X_{25}$ \\
\hline & \multirow{3}{*}{$\begin{array}{l}\text { Effectiveness of } \\
\text { production } \\
\text { management } X_{3}\end{array}$} & Prevention of pollution and cross contamination $X_{31}$ \\
\hline & & Production operation management $X_{32}$ \\
\hline & & Packaging operation management $X_{33}$ \\
\hline & \multirow{9}{*}{$\begin{array}{c}\text { Effectiveness of } \\
\text { quality assurance } \\
\text { and quality control } \\
X_{4}\end{array}$} & Quality control and laboratory management $X_{41}$ \\
\hline & & Material and product release $X_{42}$ \\
\hline & & Continuous stability study $X_{43}$ \\
\hline & & Change control $X_{44}$ \\
\hline & & Processing bias $X_{45}$ \\
\hline & & Corrective and preventive action $X_{46}$ \\
\hline & & Supplier evaluation and approval $X_{47}$ \\
\hline & & Product quality review $X_{48}$ \\
\hline & & Complaints and adverse reaction reports $X_{49}$ \\
\hline & \multirow{2}{*}{$\begin{array}{l}\text { Effectiveness of } \\
\text { commissioned } \\
\text { production and } \\
\text { inspection } X_{5}\end{array}$} & Commissioned production $X_{51}$ \\
\hline & & Commissioned inspection $X_{52}$ \\
\hline & \multirow{2}{*}{$\begin{array}{c}\text { Effectiveness of } \\
\text { Issue and recall of } \\
\text { products } X_{6}\end{array}$} & Issue of products $X_{61}$ \\
\hline & & Recall of products $X_{62}$ \\
\hline & \multirow{2}{*}{$\begin{array}{l}\text { Effectiveness of } \\
\text { self-checking } X_{7}\end{array}$} & Self-checking plan $X_{71}$ \\
\hline & & Self-checking report $X_{72}$ \\
\hline
\end{tabular}

Although the GAHP method is able to achieve the goal of multi person decision weight, considering that when judging the relative importance weights of two indexes, decision makers may not judge through the numbers of "one to nine", thus, judging from an interval-value may better reflect the intent of decision makers. It is necessary to clear each weight of every expert, because different experts have different experience, different status and different weight.

The core content of GAHP method is the determination of relative importance weights between two indexes, so the determination of relative importance weights between two indexes should be focused on the discussion.

Assuming that a total number of $K$ experts participates in the effectiveness of the quality management system of manufacturing enterprises, then in the weight determination process of index system, the relative importance interval-value between $x_{g}$ and $x_{h}$ in the same level gotten by $K$ expert $(k=1,2, \ldots, K)$ is $\left[d_{1 e}^{(k)}, d_{2 e}^{(k)}\right]\left(d_{2 e}^{(k)} \geq d_{1 e}^{(k)}\right)$ and the weights of each experts are $c_{k}$ $(k=1,2, \ldots, K)$ respectively. Thus, the comparison value of relative importance of $x_{g}$ and $x_{h}$ is:

$f_{g, h}=\frac{1}{2} \cdot \frac{\sum_{k=1}^{K}\left\{\left[d_{2 e}^{(k)}\right]^{2}-\left[d_{1 e}^{(k)}\right]^{2}\right\} \cdot c_{k}}{\sum_{k=1}^{K}\left[d_{2 e}^{(k)}-d_{1 e}^{(k)}\right] \cdot c_{k}}$.

After determining the comparison value of relative importance of two indexes in the same level, according to the steps and requirements of AHP methods, the weight of evaluation index 
system of the effectiveness of the quality management system of manufacturing enterprises can be determined.

The weight of $X_{i}$ in the evaluation index system on the effectiveness of the quality management system of manufacturing enterprises is $X_{i}(i=1,2, \ldots, 7)$, first-class index weight vector $A=\left(w_{1}, w_{2} \ldots, w_{7}\right)$ and meet the condition of $w_{i} \geq 0$, and $\sum_{i=1}^{7} w_{i}=1$; the set formed by the weight of second-class indexes to the target layers is $X_{i s}\left(i=1,2, \ldots, 7 ; s=1,2, \ldots, n_{i}\right)$, secondclass index weight vector $W_{i j}=\left(w_{i 1}, w_{i 2}, \ldots, w_{i n}\right)$ and meet the condition of $w_{i s} \geq 0$ and $\sum_{s=1}^{n_{i}} w_{i s}=1$.

\section{Evaluation index system construction on the effectiveness of the quality management system of manufacturing enterprises based on interval-valued hesitation fuzzy set}

As shown in Table 1, evaluation index system of the effectiveness of the quality management system of manufacturing enterprises involves five first-class indexes and twenty-seven secondclass indexes among which the value of each index is determined by the understanding of experts to give the interval-valued hesitation fuzzy set [5-7]. Assuming that there is a total of $K$ experts participate in the evaluation on the effectiveness of the quality management system of manufacturing enterprises, then, $K$ expert $(k=1,2, \ldots, K)$ gives an interval-valued hesitation fuzzy set $\tilde{X}_{i j}$ to a second-class index $x_{i j}$, with $\tilde{X}_{k i j}=\left\{\left\langle x, h_{k}(x)\right\rangle\right\}$, and $\operatorname{suph}_{k}(x) \leq 1$.

Based on these, the interval-valued hesitation fuzzy set of second-class index $x_{i j}$ given by these $K$ experts is:

- Define the score function of $\tilde{X}_{i j}$ as $s\left(\tilde{X}_{i j}\right)$, then:

$s\left(\tilde{X}_{i j}\right)=\sum_{k=1}^{K} \frac{1}{2 K}\left(h_{k i j}^{-}(x)+h_{k i j}^{+}(x)\right)$.

Make the score function of $\tilde{X}_{i j}, s\left(\tilde{X}_{i j}\right)$ as the index value of second-class index. The set formed by all these index values of second-class indexes is $D_{i j}(i=1,2, \ldots, m ; j=1,2, \ldots, n)$.

Based on these, the evaluation on the effectiveness of the quality management system of manufacturing enterprises can be carried out for a specific region. Take $B$ as the effectiveness of the quality management system of manufacturing enterprises, then:

$B=D_{i j} \otimes W_{i j}$

\section{Conclusion}

The research is aimed at effectiveness evaluation of manufacturing enterprise quality management system to improve the quality management system of manufacturing enterprise. Based on acquaintance of effectiveness of quality management system of manufacturing enterprise, the evaluation index system is structured by confirmation of production conditions and other seven respects which include effectiveness of validation, effectiveness of document management, effectiveness of production management, effectiveness of quality assurance and quality control, effectiveness of commissioned production and inspection, effectiveness of Issue and recall of products and effectiveness of self-checking; the assessment model of effectiveness of quality management system of manufacturing enterprise based on interval-valued hesitation fuzzy set is structured and the feasibility of theoretical research was validated by concrete cases. 


\section{References}

[1] Frems D., Janssns M., Madhok A., et al. Toward an integrative perspective on alliance governance: connecting contract design, trust dynamics and contract application. Academy of Management Journal, Vol. 51, Issue 6, 2008, p. 1053-1078.

[2] Dyer J. H., Chu W. The role of trustworthiness in reducing transaction costs and improving performance: empirical evidence from the United States, Japan and Korea. Organization Science, Vol. 14, Issue 1, 2003, p. 57-68.

[3] Hwang Bon Gang, Zhao Xianbo, Gay Mindy Jiang Shu Public private partnership projects in Singapore: Factors, critical risks and preferred risk allocation from the perspective of contractors. International Journal of Project Management, Vol. 31, Issue 3, 2013, p. 424-433.

[4] Sodeikat Christian, Dauber Schmidt Christoph Corrosion monitoring of RC-structures for public private partnership projects. Making durability visible. Beton und Stahlbetonbau, Vol. 101, Issue 12, 2006, p. 932-942.

[5] Yuan Jingfeng, Zeng Alex Yajun, Skibniewski Miroslaw J., Li Qiming Selection of performance objectives and key performance indicators in public-private partnership projects to achieve value for money. Construction Management and Economics, Vol. 27, Issue 3, 2009, p. 253-270.

[6] Augustínová Edita, Daubner Michal Performance measurement and management of public-private partnership projects. International Multidisciplinary Scientific GeoConference Surveying Geology and Mining Ecology Management, Vol. 2, Issue 3, 2013, p. 239-246.

[7] Ng Angie, Loosemore Martin Risk allocation in public private partnership (PPP) projects: the new southern railway project. Proceedings of 22nd Annual Association of Researchers in Construction Management Conference, Vol. 2, 2006, p. 573-580. 